\title{
FEATURES OF COMMON CULTURAL COMPETENCE DEVELOPMENT AT BACHELORS MAJORING IN «PHYSICAL CULTURE AND SPORT»
}

(C) 2017

Serper Sergey Aleksandrovich, candidate of economical sciences, doctoral candidate of SSUSSE

Buranok Oleg Mikhailovich, doctor of philological sciences, doctor of pedagogical sciences, professor, head of Russian Literature, Foreign Literature and Methods of Teaching Literature Department

Samara State University of Social Sciences and Education (Samara, Russian Federation)

Abstract. The paper deals with features of common cultural competence development at bachelors majoring in «Physical culture and sport». The federal state educational standard of the third generation, approved by the Ministry of Education and Science of the Russian Federation, involves common cultural competence development at bachelors majoring in «Physical Culture and Sports». This competence is important for the implementation of the program that develops a modern expert and trainer's personality. The value of common cultural competence in the system of modern education is increasing due to the personality-oriented education paradigm establishment when the society requires active, capable of self-development and self-education professionals, especially in areas that are vital for the development of the Russian society and the state. The paper shows that the development of fitness has formed a fitness pedagogy: it is necessary to determine a set of professional and general cultural competence, content and curriculum framework for future professionals in the field of fitness as well as what common cultural competence contribute to the training of future experts in fitness and how professional and general cultural competence interact in the educational process. Solving this problem will allow to reform the system of experts' training and will help to achieve national objective to preserve the nation's health.

Keywords: common cultural competence; higher education; bachelor's degree; physical culture and sport; training of bachelor's; pedagogical education; personality-oriented education paradigm; fitness pedagogy; professional competence; educational process; health care.

УДК 373.5.016: 51: 81’246.2 (571.56)

\section{ОСОБЕННОСТИ ФОРМИРОВАНИЯ У ШКОЛЬНИКОВ МАТЕМАТИЧЕСКИХ ПОНЯТИЙ НА ОСНОВЕ БИЛИНГВАЛЬНОГО ОБУЧЕНИЯ}

(C) 2017

Спиридонова Наталья Ивановна, научный сотрудник

Институт национальных школ Республики Саха (Якутия) (г. Якутск, Российская Федерациия)

Аннотащия. В статье рассматривается процесс формирования математических понятий у школьников в условиях билингвального (двуязычного) обучения. Описываются результаты экспериментальной работы, включающей анкетирование учащихся и учителей, направленной на выявление предпочтения родного или русского языка как языка обучения, проверочную работу по выявлению уровня сформированности математического языка у учащихся 5-6 классов на основе двух языков. В результате анализа психологопедагогической и учебно-методической литературы, содержания диссертационных работ по теме исследования выявлены особенности организации билингвального образовательного процесса по формированию математических понятий в образовательных организациях Республики Саха (Якутия), который протекает поэтапно и реализуется посредством совокупности учебных действий. Определено, что основным средством выполнения действий, соответствующих этапам формирования математических понятий, может являться билингвальный дидактический комплекс, направленный на формирование понятий и развитие математической речи учащихся. Полученные в ходе исследования материалы могут быть положены в основу проектирования методики формирования математических понятий в условиях двуязычия, создания учебнометодической литературы, а также использованы учителями школ с родным языком обучения.

Ключевые слова: билингвальное образование; государственный язык; математическая грамотность; математическая речь; математический язык; математическое понятие; методика формирования понятий; модели билингвального обучения; Республика Саха (Якутия); родной язык; этапы формирования математических понятий; язык обучения.

На современном этапе развития российского образования возросла роль человеческого капитала, который является одним из ключевых факторов развития общества, экономики и государства. Как отмечено в Концепции федеральной целевой программы развития образования на 2016-2020 годы, формирование конкурентоспособной личности является основной задачей современной школы. Умение использовать полученные знания и навыки в решении жизненных проблем определяют эффективность образования и характеризуют учащегося как конкурен- тоспособную личность. В мониторинговых исследованиях Международной программы по оценке образовательных достижений учащихся PISA (Programme for International Student Assessment) приводится оценка способности пятнадцатилетних школьников применять в реальной жизни знания, полученные в школе, которая определяется по трем параметрам: грамотность чтения, математическая грамотность, естественнонаучная грамотность. В этих исследованиях под математической грамотностью понимают «способность индивидуума формулировать, приме- 
нять и интерпретировать математику в разнообразных контекстах. Она включает математические рассуждения, использование математических понятий, процедур, фактов и инструментов, чтобы описать, объяснить и предсказать явление. Она помогает людям понять роль математики в мире, высказывать хорошо обоснованные суждения и принимать решения, которые должны принимать конструктивные, активные и размышляющие граждане» $[1 ; 2]$. Эти исследования показывают, что обучение математике играет существенную роль в формировании у школьников языковой культуры. И.Ф. Тесленко под математическим языком понимает систему, включающую средства родного языка, математическую терминологию, символику, графики, схемы и т.п. [3], то есть математический язык является средством познания окружающего мира. Как отмечено в «Философском словаре» [4], понятие является «...одной из форм отражения мира в мышлении, с помощью которой познается сущность явлений, процессов, обобщаются их существенные стороны и признаки». Другими словами, для овладения математическим языком и развития математической речи в процессе образовательной деятельности необходимо формировать в мышлении школьников математические понятия, которые являются отображением реальных объектов окружающей действительности.

В Республике Саха (Якутия), где с 1992 года установлены два государственных языка, наряду с русским языком в качестве языка обучения используется родной язык учащихся - якутский язык (язык саха). На 2014-2015 учебный год численность обучающихся на родном (якутском) языке составляет 52411 человек, не намного выше количество обучающихся на русском языке - 78158 человек. В местах компактного проживания малочисленных народов Севера юридически закреплены официальные языки: эвенский, эвенкийский, юкагирский, долганский и чукотский, которые изучаются как учебный предмет. Количество детей, изучающих якутский язык, составляет 23586 человек, эвенский - 945, эвенкийский - 364, юкагирский - 59, чукотский - 33, долганский язык в настоящее время не изучается как предмет [5]. Поэтому в условиях билингвального обучения формирование математических понятий, которые являются гарантией качественного усвоения знаний, предметного содержания и развития лингвистических компетенций школьников, приобретает особую актуальность.

В нашем исследовании поставлена цель - выявить особенности процесса формирования математических понятий у учащихся в условиях билингвального обучения (на примере школ Республики Саха (Якутия)).

Для выявления этих особенностей мы рассмотрели психологическую, педагогическую литературу, диссертационные работы по проблеме формирования научных понятий, в частности по математике. В работах таких психологов, как Д.Н. Богоявленский, Л.С. Выготский, П.Я. Гальперин, В.В. Давыдов, Е.Н. Кабанова-Меллер, Н.Я. Менчинская, Н.Ф. Талызина, М.А. Холодная, М.Н. Шардаков и др., описываются и теоретически обосновываются различные способы формирования научных понятий у школьников. Их исследования направлены на решение общей про- блемы, но охватывают различные его аспекты. Труды М.И. Башмакова, В.А. Гусева, О.Б. Епишевой, Ю.М. Колягина, Г.И. Саранцева, 3.И. Слепкань, А.А. Столяра, А.В. Усовой и др., изданные в форме учебно-методической литературы, также посвящены этой проблеме. Эта тема затрагивается также в диссертационных работах А.С. Аскерова, Л.В. Виноградовой, М.Б. Волович, Т.К. Лепмана, З.П. Мотовой, И.В. Ситниковой, Л.А. Черных и др. Некоторые аспекты формирования понятий в условиях билингвального обучения были рассмотрены в работах Г.Ш. Азитовой, А.В. Габдулхакова, В.В. Кондратьева, А.П. Майорова, А.И. Петровой, Л.Л. Салеховой, Н.К. Туктамышова, А.И. Усмановой и др.

Проанализировав исследования и публикации, в которых рассматривались аспекты формирования математических понятий, мы выделили работу И.В. Ситниковой [6], в которой автор системно подошел к решению данного вопроса. Также мы опирались на работу А.И. Петровой [7], в которой были научно обоснованы теоретические основы усвоения математических знаний в условиях двуязычного образования. Нашим ориентиром послужила и работа В.А. Габдулхакова [8], в которой была конкретизирована сущность математических понятий и определены принципы их формирования в двуязычной среде.

В своем исследовании И.В. Ситникова [6] разработала концепцию формирования понятий, представляющую собой определенную систему требований к рассматриваемому процессу, применение которой может обеспечить высокое качество усвоения учениками основных понятий математики и будет способствовать повышению качества их математических знаний и умений. В результате теоретикоэкспериментального исследования она пришла к следующим выводам:

1. Основой методической концепции формирования математических понятий является системное рассмотрение содержания этапов процесса формирования понятий, средств и форм его реализации, логических вариантов образования понятий и психологические рекомендации по их усвоению.

2. Этапами формирования математических понятий в школе являются: мотивация их введения; выявление существенных свойств понятия, составляющих определение; формулировка определения; усвоение логической структуры определения; применение понятия; систематизация понятий.

3. Каждый этап представляется определенной совокупностью действий, среди которых: создание учебно-проблемной ситуации; формулировка основной учебной задачи; выделение существенных свойств понятия, составляющих его определение; распознавание объектов, принадлежащих и не принадлежащих понятию; выведение следствий из принадлежности объекта понятию; выполнение действий, лежащих в основе применения понятия (замена термина его определением, замена определения понятия другой совокупностью существенных свойств и др.); установление связей, зависимостей между отдельными понятиями и теоремами и т.д.

4. Основным средством формирования действий, адекватных этапам процесса формирования понятий являются системы упражнений. 
5. Использование разработанной методики позволяет технологизировать процесс формирования математических понятий в школе и диагностировать усвоение понятия на каждом из этапов этого процесca.

Как отмечают Ф.В. Габышева, С.С. Семенова [9], в общеобразовательных организациях Республики Саха (Якутия) в зависимости от статуса родного языка и социолингвистической ситуации выделяются пять моделей языка образования:

1. Обучение ведется на родном языке учащихся на протяжении всего периода обучения. Данная модель соответствует обучению на русском языке учащихся, у которых он является родным (первым) языком.

2. Обучение на родном языке $(1-4,1-7,1-9$ классы) с последующим переходом на русский язык с определенной ступени. Модель действует в общеобразовательных организациях с якутским языком обучения.

3. Язык обучения - неродной, государственный язык, изучение родного языка организуется в качестве учебного предмета. Данная модель распространена: 1) в обучении детей саха на русском языке в условиях поликультурной среды; 2) в обучении детей коренных малочисленных народов Севера на русском языке или на языке саха.

4. Язык обучения - русский или язык саха, а изучение родного (этнического) языка в учебном плане не предусмотрено, родной язык используется только в неформальном общении, преимущественно в семье.

5. В перспективе планируется реализовать модель, в которой языками обучения будут выступать родной, русский и иностранные языки.

Эти модели реализуются в образовательных организациях коренных малочисленных народов Севеpa, организациях с обучением на языке саха, а также в организациях с русским (неродным) и русским (родным) языком обучения посредством образовательных программ начального и основного общего образования, разработанных на основе федеральных государственных требований и образовательных стандартов с учетом региональных и этнокультурных особенностей Республики Саха (Якутия) [1014]. Для начальных классов по заказу Министерства образования Республики Саха (Якутия) осуществляется перевод учебников, включенных в федеральный перечень, создаются учебные пособия на родном языке учащихся, разрабатываются методические пособия для учителей.

В нашем исследовании мы рассматривали процесс обучения, организованный в соответствии со второй моделью, предложенной Ф.В. Габышевой и C.С. Семеновой. На основании этой модели, начиная с пятого класса, обучение учебным предметам происходит на билингвальной основе, то есть языками обучения выступают родной и русский языки.

Так как показателем успешного усвоения системы математических понятий является владение математическим языком, в 2014-2015 учебном году в 5-6 классах школ с якутским языком обучения мы провели экспериментальную работу по выявлению уровня сформированности математического языка на основе государственных языков. В эксперименте приняли участие 120 учеников, 30 из которых в начальных классах обучались на русском языке, а родной язык изучали как учебный предмет. В начале эксперимента мы провели анкетирование, которое было направлено на выявление предпочтения учащимися языка (родного, русского) как языка обучения на уроках математики. Ответы учеников на вопрос анкеты: «На каком языке вам легче усваивать знания на уроках математики?» представлены в таблице 1.

Таблица 1 - Предпочтение языка в качестве языка обучения на уроках математики

\begin{tabular}{|c|l|c|c|c|}
\hline № & Варианты ответов & $\begin{array}{c}5 \text { класс } \\
\text { (\%) }\end{array}$ & $\begin{array}{c}\text { 6 класс } \\
\text { (\%) }\end{array}$ & $\begin{array}{c}5-6 \text { кла- } \\
\text { ссы (\%) }\end{array}$ \\
\hline 1 & На якутском языке & 9 & 4 & 7 \\
\hline 2 & На русском языке & 38 & 22 & 31 \\
\hline 3 & $\begin{array}{l}\text { Одинаково } \\
\text { на обоих языках }\end{array}$ & 30 & 22 & 26 \\
\hline 4 & $\begin{array}{l}\text { Воздержались } \\
\text { от ответа }\end{array}$ & 23 & 52 & 36 \\
\hline
\end{tabular}

Результаты анкетирования говорят о том, что 7\% респондентов лучше усваивают знания на родном языке, $30 \%$ - на русском языке, $26 \%$ - на двух языках, а $36 \%$ опрошенных не могут конкретно определить, на каком языке им лучше изучать математику.

Анкетирование учителей выявило, что на уроках математики в 5-6 классах они часто используют якутский язык в качестве языка обучения: при изучении нового материала, его обобщении и систематизации, для контроля и коррекции знаний, умений и навыков обучающихся, а также на таких этапах урока, как подготовка учащихся к усвоению нового материала, усвоение новых знаний и способов действий, первичная проверка понимания изученного, обобщение и систематизация знаний, коррекция знаний и способов действий, рефлексия и оценивание (подведение итогов). Кроме того, учителя-предметники отмечают, что некоторые дети при устной речи в основном используют родной язык, а также акцентируют внимание на том, что в пятый класс дети приходят из разных школ, в том числе из тех, в которых языком обучения в начальных классах мог быть один из государственных языков.

Для выявления уровня сформированности математического языка у учащихся 5-6 классов на основе двух языков была проведена проверочная работа. Усвоение математического языка учащимися определялось по уровню владения семантическими (умение объяснять, понимать значение термина, символа) и синтаксическими умениями (умение выполнять структурные преобразования над языковыми единицами), а также умениями математического моделирования.

Результаты выполнения проверочной работы отражены в табл. 2:

Результаты выполнения заданий свидетельствуют о том, что:

- количество ответов, в которых правильно и полно были указаны значения терминов и символов; названы математические объекты и классы объектов соответствующим термином; правильно выполнены упражнения на запись и чтение различных математических выражений, в 5 классе составило 27\%, в 6 классе - $16 \%$; 
- количество ответов, в которых выделена лишь часть значений терминов и символов, допущены незначительные ошибки при записи, преобразовании и построении математических выражений, в 5 классе составило $11 \%$, в 6 классе - 3\%. Ученики, которые дали такие ответы, имеют общие представления о математических терминах и символах, умеют ими оперировать, но знания ими еще недостаточно усвоены;

- количество неправильных ответов (или ответ отсутствует) в 5 классе составило $62 \%$, в 6 классе $81 \%$. Такие ответы дали учащиеся, не усвоившие полностью значения терминов и символов, а следовательно, не усвоившие и соответствующие им понятия.

Таблица 2 - Результаты проверочной работы по выявлению уровня сформированности математического языка по основным видам умений

\begin{tabular}{|c|c|c|c|c|}
\hline \multirow[b]{2}{*}{ Вид умения } & \multirow[b]{2}{*}{ 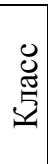 } & \multicolumn{3}{|c|}{ Количество ответов (\%) } \\
\hline & & $\begin{array}{c}\text { Пра- } \\
\text { виль- } \\
\text { ные }\end{array}$ & $\begin{array}{c}\text { Частично } \\
\text { правиль- } \\
\text { ные }\end{array}$ & $\begin{array}{c}\text { Непра- } \\
\text { виль- } \\
\text { ные }\end{array}$ \\
\hline \multirow{2}{*}{$\begin{array}{l}\text { Объяснять, понимать } \\
\text { значение термина }\end{array}$} & 5 & 60 & - & 40 \\
\hline & 6 & 66 & - & 34 \\
\hline \multirow{2}{*}{$\begin{array}{l}\text { Объяснять, понимать } \\
\text { значение символа }\end{array}$} & 5 & 34 & 5 & 61 \\
\hline & 6 & 15 & 7 & 78 \\
\hline \multirow{2}{*}{$\begin{array}{l}\text { Читать символические } \\
\text { записи }\end{array}$} & 5 & 2 & 9 & 89 \\
\hline & 6 & 11 & 4 & 85 \\
\hline \multirow{2}{*}{\begin{tabular}{|l|} 
Записывать словесные \\
выражения с помощью \\
математических знаков \\
\end{tabular}} & 5 & 33 & 10 & 57 \\
\hline & 6 & 18 & 1 & 81 \\
\hline \multirow{2}{*}{$\begin{array}{l}\text { Выполнять преобразо- } \\
\text { вания символических } \\
\text { выражений }\end{array}$} & 5 & 38 & 36 & 26 \\
\hline & 6 & 0 & 5 & 95 \\
\hline \multirow{2}{*}{$\begin{array}{l}\text { Строить выражения } \\
\text { с помощью заданных } \\
\text { символов } \\
\end{array}$} & 5 & 13 & 15 & 72 \\
\hline & 6 & 4 & 1 & 95 \\
\hline \multirow{2}{*}{\begin{tabular}{|l|} 
Строить математиче- \\
скую модель ситуации, \\
описанной словесно \\
\end{tabular}} & 5 & 8 & 0 & 92 \\
\hline & 6 & 1 & 1 & 98 \\
\hline \multicolumn{2}{|l|}{ Итого (5 класс): } & 27 & 11 & 62 \\
\hline \multicolumn{2}{|l|}{ Итого (6 класс): } & 16 & 3 & 81 \\
\hline
\end{tabular}

На основе результатов анкетирования участников билингвального образовательного процесса и анализа результатов проверочной работы по выявлению уровня сформированности математического языка мы выявили, что учащиеся 5-6 классов усваивают математические понятия на основе двух языков. Используя родной язык, они лучше справились с заданиями, касающимися символов операций и отношений. Было определено также, что детям легче объяснить на родном языке термины, показывающие отношения математических объектов. В 6 классе умение читать символические записи улучшается, особенно на родном языке. В ходе эксперимента мы установили также, что дети, используя русский язык, лучше записывают словесные выражения с помощью математических знаков, выполняют преобразования символических выражений, строят выражения с помощью заданных символов и моделируют словесную ситуацию.

Кроме того, обобщая результаты экспериментальной части нашего исследования, следует отме- тить, что у школьников происходит понижение уровня сформированности семантических (объяснять и понимать значение термина, символа) и синтаксических умений (записывать словесные выражения с помощью математических знаков). То есть языковой барьер, который затрудняет процесс формирования математического языка на русском языке, постепенно снижает уровень развития математической подготовки учащихся. Наблюдение в ходе эксперимента показало, что для преодоления этого барьера ученики прибегают к помощи родного языка, а именно просят учителя объяснить значение нового понятия сначала на родном языке, затем сформированное математическое понятие объясняют посредством математического языка, выстроенного на основе русского языка. Например, опыт учителей и наблюдение за образовательным процессом в Республике Саха (Якутия) показывает, что в 5-6 классах учитель часто прибегает к помощи родного языка учащихся, а начиная с 7 класса потребность в дополнительном разъяснении учебного материала постепенно уменьшается. То есть при реализации переходной модели билингвального обучения математике, действующей в образовательных организациях с якутским языком обучения, учащиеся лучше усваивают предметные и языковые знания, опираясь на родной (якутский) язык. При этом качество полученных знаний зависит от уровня их языковой, лингвистической, коммуникативной компетентности, а также от профессионализма учителя. В связи с этим для систематизации процесса речемыслительной деятельности учащихся возникает потребность в разработке и научном обосновании методики формирования математических понятий на основе билингвального обучения [15].

На основе исследований особенностей организации билингвального образовательного процесса в рамках проекта «Два языка - два крыла» Научноисследовательского института национальных школ Республики Саха (Якутия) был разработан «Якутскорусский, русско-якутский терминологический словарь для учащихся основной школы» [16] и в 2016 году издан при поддержке Министерства образования Республики Саха (Якутия). Данный словарь составлен на основе «Русско-якутского толкового словаря математических терминов» (Егоров И.Г., Петров П.П., Петрова А.И.) [17], включает 349 терминов, является одним из средств реализации переходной модели билингвального обучения математике. При создании словаря нами были отобраны математические термины, включенные в учебники по математике для 5 и 6 классов из федерального перечня учебников. Помимо этого нами были рассмотрены учебники по математике и арифметике на языке саха, изданные за период с 1936 по 2010 гг., а также были проанализированы учебники по математике (1-4 классы), включенные в 12 учебно-методических комплектов для начальной школы. Мы классифицировали термины как переводимые, непереводимые, употребляемые с фонетизацией, спорные. По инициативе нашего института было сформировано общественно-профессиональное сообщество по проблемам билингвального математического образования. В ходе работы общественно-профессионального сообщества, которое объединяет учителей математики, лингвистов, математиков и ученых-методистов, 
был проведен ряд круглых столов по обсуждению проблем школьной математической терминологии [15].

А.И. Петрова [7] в своем исследовании выявила и теоретически обосновала дидактические особенности усвоения математических знаний в процессе билингвального образования. Она отметила, что в процессе обучения математике учащиеся должны:

- знать: четкий алгоритм представлений структуры, объема и содержания понятий; структуру определения, его роль и место в школьном курсе математики; определение опорных понятий;

- уметь: классифицировать понятия; расчленять определение на составные части; составлять определение понятия по схеме: «определяемое понятие»«предикат» (сказуемое) - «ближайшее родовое понятие» и «видовые отличия»; выявлять, подходит ли данный объект под определение понятия; переходить от словесной формулировки математических предложений к их символической записи; видеть сходство и различия в логической структуре определений и теорем.

А.И. Петрова считает также, что в условиях двуязычия при формировании математических понятий необходимо учитывать:

- специфику различных психолого-дидактических концепций усвоения знаний учащимися и концепций билингвального образования;

- языковые особенности, тесно связывая работу по усвоению математических знаний с работой по овладению знаковыми системами математического языка;

- имеющийся у школьников жизненный опыт, создавая при этом научное представление о том или ином понятии по дидактической схеме: выявление обыденного, снятие обыденного, формирование научного. При этом жизненные представления учащихся не должны противоречить научному пониманию, в противном случае требуется существенная корректировка обыденного знания [18];

- специфику понятия, его значимость, сложность, возрастные и учебные возможности школьников при выборе пути введения математического понятия конкретно-индуктивным или абстрактно-дедуктивным методом.

Кроме этого, на основе положений теории познания и выявленных особенностей усвоения математических знаний А.И. Петрова разработала специфическую методику введения математических понятий в условиях билингвальной национальной школы, представляющую собой систему следующих методов:

- использование интеграционных связей математики с другими научными дисциплинами;

- применение социокультурного материала, использование жизненного опыта учащихся;

- использование интеграционных связей математики с родным и русским языками, применение элементов сравнительного языкознания;

- этимологический подход при изучении математической терминологии, работа над словом-термином и символом, чтобы создать научное представление о том или ином понятии по дидактической схе- ме: выявление обыденного - снятие обыденного формирование научного.

По данной методике в билингвальных математических классах были проведены специально систематизированные практические занятия, в которых оптимально сочетались словесные, наглядные и практические, репродуктивные и поисковые методы и приемы обучения. Данная система занятий включала в себя: учебно-практическое задание; процесс выполнения этого задания; обобщение результата в практической деятельности; абстрагирование; формулировку математических понятий; систематизацию учебного материала; интерпретацию полученных знаний, характеризующих структуру познавательной деятельности школьников на практических занятиях по математике.

Для исследования феномена, вынесенного в название нашей статьи, мы использовали также результаты диссертационного исследования А.В. Габдулхакова [8], который разработал и научно обосновал дидактические условия обучения учащихся татарских гимназий с этнокультурным компонентом математическим понятиям в двуязычной среде. Он выявил следующие педагогические условия личностноразвивающего обучения, направленного на формирование математических понятий в условиях двуязычия:

- мотивация введения новых терминологических понятий;

- семантизация содержания понятий, отсутствующих у обучаемых на татарском языке;

- дифференциация беспереводных и переводных способов семантизации понятий (на основе приемов межфразовых связей, анализа смысловой структуры текста, приемов обнаружения тематического центра высказывания и др.);

- актуализация в проблемно-коммуникативных ситуациях специальных (математических) знаний и математических ценностей;

- развитие двуязычной речевой деятельности школьников на основе данных, отражающих реальную картину коммуникативной деятельности обучаемых;

- использование в речевой работе приемов формирования коммуникативного ядра, стимулирующего творческую, исследовательскую деятельность учащихся;

- реализация приемов интеграции содержания языкового и математически направленного характеpa, а также приемов, позволяющих сочетать индивидуальные и групповые формы обучения;

- организация коммуникативной деятельности обучаемых на основе учета преобладающего типа личностной направленности, индивидуально-психологических особенностей;

- создание национально-культурных представлений об отдельных математических понятиях;

- постоянное использование понятий в практических формах деятельности;

- систематичность и целенаправленность деятельности учителя по управлению процессом усвоения знаний, обеспечивающей правильное сочетание наглядно-образного, словесно-логического и дей- 
ственно-практического компонентов мышления учащихся.

Выявленные условия А.В. Габдулхаков учитывает при разработке педагогической модели и технологии обучения математическим понятиям в двуязычной среде, которая реализуется по следующему компонентному алгоритму: 1) мотивационно-целевой, 2) информационно-познавательный, 3) творческо-деятельностный, 4) контрольно-оценочный.

На основе проведенного анализа научных исследований [6-8] по формированию математических понятий, результатов анкетирования и экспериментальной работы по определению уровня сформированности математического языка мы выявили следующие особенности, которые обеспечивают качественное усвоение математических понятий на основе билингвального обучения:

1. Усвоение математических понятий в условиях национально-русского двуязычия должно осуществляться на основе специально разработанной методики, которая учитывает специфику различных психолого-дидактических концепций усвоения знаний обучающимися и концепций билингвального образования; обеспечивает правильное сочетание нагляднообразного, словесно-логического и действенно-практического компонентов мышления; использует интеграционные связи математики с другими учебными дисциплинами.

2. Процесс формирования математических понятий в школе с родным языком обучения должен протекать поэтапно и осуществляться посредством выполнения учащимися и учителем совокупности определенных действий. Утверждая это, мы придерживались алгоритма формирования понятий, предложенного А.В. Гадулхаковым [8], характеризуя при этом каждый этап совокупностью действий, учитывающей особенности познавательной, речемыслительной деятельности учащихся и билингвального образовательного процесса:

1) Мотивационно-ц̧елевой этап, на котором необходимо мотивировать учеников к введению новых терминологических понятий, создавать учебнопроблемную ситуацию, формулировать основную учебную задачу. При выборе наиболее оптимального маршрута введения математического понятия (конкретно-индуктивным или абстрактно-дедуктивным методом) нужно учитывать специфику понятия, возрастные и учебные возможности школьников. Необходимо организовать коммуникативную деятельность детей на основе учета их индивидуальнопсихологических особенностей, актуализировать специальные (математические) знания и математические ценности в проблемно-коммуникативных ситуациях с реализацией приемов интеграции содержания языкового и математически направленного характера, а также приемов, позволяющих сочетать индивидуальные и групповые формы обучения.

2) Информационно-познавательный этап. На этом этапе школьники должны выявить существенные свойства понятия, составляющих его определение, распознать объекты, принадлежащие и не принадлежащие понятию, классифицировать понятия, сформулировать определение, усвоить логическую структуру определения и др. Здесь нужно обратиться к жизненному опыту учащихся при создании научного представления о математическом понятии; сформировать математический язык на двух языках (работать с терминами и символами); объяснить значение понятий (терминов), не сформированных у обучаемых на родном языке; дифференцировать беспереводные и переводные способы семантизации понятий (на основе приемов межфразовых связей, анализа смысловой структуры текста, приемов обнаружения тематического центра высказывания и др.); по возможности создать национально-культурные представления о математических понятиях.

3) Творческо-деятельностный этап. На данном этапе учащиеся применяют в практической деятельности усвоенные понятия, для чего выполняют такие действия, как замена определения понятия другой совокупностью существенных свойств, вывод следствия из принадлежности объекта понятию, расчленение определения на составные части, перевод формулировки математических предложений к их символической записи и др. Здесь целесообразно применять социокультурный материал, использовать жизненный опыт учащихся; развивать математическую речь на основе родного и русского языков; использовать в речевой работе приемы формирования коммуникативного ядра, стимулирующего творческую, исследовательскую деятельность учащихся; систематически и целенаправленно управлять процессом усвоения знаний обучающимися.

4) Контрольно-оченочный этап. На этом этапе учащиеся систематизируют в своем сознании математические понятия, устанавливают связи и зависимости между ними, конструируют новое понятие на основе изученных, видят сходство и различия в логической структуре определений и др. Здесь необходимо контролировать и оценивать правильность использования математического языка, не допуская смешивания естественных языков в процессе речемыслительной деятельности учащихся.

3. Основным средством реализации действий, соответствующих этапам формирования математических понятий на основе билингвального обучения, является билингвальный дидактический комплекс, направленный на формирование математических понятий и развитие математической речи, включающий в себя систему речемыслительных упражнений и билингвальный терминологический словарь для учащихся основной школы.

Считаем, что полученные в ходе нашего исследования материалы могут быть положены в основу проектирования методик формирования математических понятий и развития математической речи в условиях двуязычия, создания новой учебно-методической литературы, а также использованы учителями школ с родным языком обучения.

\section{СПИСОК ЛИТЕРАТУРЫ:}

1. Международная программа по оценке образовательных достижений учащихся PISA (Programme for International Student Assessment) [Электронный pecypc] // http://oecd.org/edu/pisa.

2. Результаты Международной программы по оценке образовательных достижений учащихся PISA. [Электронный ресурс] // Центр оценки качества образования. - http://centeroko.ru. 
3. Тесленко И.Ф. Научно-техническая революция и математика в школе. Киев, 1973. $31 \mathrm{c}$.

4. Философский словарь / под ред. М.М. Розенталя, П.Ф. Юдина. М., 1963. 544 с.

5. Габышева Ф.В., Тен Л.Б., Сивцева М.В. Образование республики в цифрах и фактах. Якутск: Медиа-Холдинг Якутия. IV выпуск. 2015. 79 с.

6. Ситникова И.В. Формирование математических понятий в средней школе: дис. ... канд. пед. наук. Киров, 2000. 175 с.

7. Петрова А.И. Формирование системы двуязычного образования: история, теория, опыт: На примере математического образования в Республике Саха (Якутия): дис. ... д-ра пед. наук. М., 2004. 268 с.

8. Габдулхаков А.В. Дидактические условия обучения математическим понятиям в двуязычной среде (на материале естественнонаучных дисциплин): дис. ... канд. пед. наук. Казань, 2008. 196 с.

9. Габышева Ф.В., Семенова С.С. Развитие языковой личности в полилингвальной образовательной среде. / Динамика языковых и культурных процессов в современной России [Электронный ресурс]. Вып. 5. мат-лы V Конгресса РОПРЯЛ (Казань, 4-8 октября 2016 г.). СПб.: РОПРЯЛ, 2016. 1 электр. опт. диск (CD-R), C. 1151-1156.

10. Федеральнай государственнай үөрэх стандарда саха оскуолатыгар: [начаалынай уопсай үөрэхтээһин] = Федеральный государственный образовательный стандарт в якутской школе / Н.В. Ситникова, С.С. Семенова, Н.Н. Васильева уо.д.а.; хомуйан онордулар: Н.В. Ситникова, С.С. Семенова, Н.Н. Васильева. Ч. 1. Якутск: Бичик, 2011. 84 с.

11. Федеральный государственный образовательный стандарт в общеобразовательных учреждениях коренных малочисленных народов Севера Республики Саха; Якутия): (нач. общее образование) / Н.В. Ситникова, С.С. Семенова, Н.Н. Васильева и др.; сост.: Н.В. Ситникова, С.С. Семенова, Н.Н. Васильева. Ч. 1. Якутск: Бичик, 2011. 96 с.

12. Реализация образовательных программ начального и основного общего образования с учетом национальных, этнокультурных и иных особенностей Республики Саха (Якутия) в образовательных организациях с русским языком обучения: учебнометодическое пособие / А.И. Иванова, Е.И. Винокурова, С.С. Семенова, Н.И. Филиппова, Н.И. Спиридонова; М-во образования Респ. Саха (Якутия). Якутск: Компания «Дани-Алмас», 2016. 96 с.

13. Реализация образовательных программ с учетом национальных, этнокультурных и иных особенностей Республики Саха (Якутия) в образовательных организациях коренных малочисленных народов Севера / М-во образования Респ. Саха (Якутия), Науч.исслед. ин-т нац. школ Респ. Саха (Якутия); С.С. Семенова, Ф.М. Леханова, Р.С. Никитина и др. Якутск: Компания «Дани-Алмас», 2016. 75 с.

14. Особенности разработки образовательных программ в общеобразовательных организациях с обучением на языке саха = Саха начаалынай оскуолатыгар үөрэх бырагырааматын оноруу уратыта / Мво образования Респ. Саха (Якутия), Науч.-исслед. ин-т нац. школ Респ. Саха (Якутия); С.С. Семенова, Н.Н. Васильева, Е.И. Винокурова, В.Я. Унарова, У.М. Флегонтова, Ю.В. Андросова. Якутск: Компания «Дани-Алмас», 2016. 84 с.

15. Ченянова Н.И. Переходная модель в системе билингвального обучения математике // Дискуссия. 2013. № 11. C. 126-136.

16. Математика терминнэрин тылдьыта. 5-9 кылаас. [Якутско-русский, русско-якутский терминологический словарь для учащихся основной школы] / Саха Өрөспүүбүлүкэтин үөрэђин министиэристибэтэтэ, Саха Өрөспүүбүлүкэтин Нац. оскуолаларын чинчийэр науч. ин-т / хомуйан онордулар: Н.И. Спиридонова, А.Д. Саввинова. Дьокуускай: Компания «Дани-Алмас», 2016. 88 с.

17. Русско-якутский толковый словарь математических терминов / сост. И.Г. Егоров, П.П. Петров, А.И. Петрова. Якутск: Идз-во «Бичик», 1998. 184 с.

18. Божович Л.И. Избранные психологические труды. М.: Международная педагогическая академия, 1995. 209 с.

\title{
FEATURES OF MATHEMATICAL CONCEPTS FORMATION AT SCHOOL STUDENTS ON THE BASIS OF BILINGUAL EDUCATION
}

(C) 2017

\author{
Spiridonova Natalia Ivanovna, researcher \\ Institute of National Schools of Sakha Republic (Yakutsk, Russian Federation)
}

Abstract. The paper deals with mathematical concepts formation at students on the basis of bilingual education. It describes the results of experimental work, including the questioning of students and teachers, aimed at identifying preferences of native or the Russian language as the language of instruction, screening efforts to identify the level of mathematical language learning at pupils of 5-6 classes on the basis of the two languages. As a result of psychopedagogical and educational materials and dissertations analysis the author describes peculiarities of bilingual educational process aimed at mathematical concepts formation in educational institutions of the Republic of Sakha (Yakutia). This process takes place in stages and is implemented through the combined action. The author concludes that the primary means of performing steps corresponding to the steps of mathematical concepts formation can be bilingual didactic complex, aimed at concepts formation and pupils' mathematical speech development. The findings of the study can be used as the basis for designing a technique of mathematical concepts formation in terms of bilingualism, for educational materials creation, as well as used by school teachers with native language training.

Keywords: bilingual education; state language; mathematical literacy; mathematical speech; mathematical language; mathematical concept; concepts formation technique; bilingual training models; Republic of Sakha (Yakutia); native language; concepts formation stages; training language. 